04

\title{
Исследование динамики искрового разряда в воздухе в промежутке острие-плоскость методом теневого фотографирования
}

\author{
() К.И. Алмазова, А.Н. Белоногов, В.В. Боровков, Е.В. Горелов, И.В. Морозов, А.А. Тренькин, С.Ю. Харитонов \\ Российский Федеральный ядерный центр \\ Всероссийский научно-исследовательский институт экспериментальной фризики, \\ 607190 Саров, Россия \\ e-mail: trenkin@ntc.vniief.ru
}

(Поступило в Редакцию 5 мая 2018 г.)

С использованием метода теневого фотографирования исследована микроканальная структура искрового разряда в промежутке острие-плоскость длиной $1.5 \mathrm{~mm}$. Зарегистрирована динамика разряда на временах от единиц до сотен наносекунд, включающая развитие микроканалов от острия вглубь разрядного промежутка, ветвление, перемыкание разрядного промежутка, расширение микроканалов, формирование общего фронта ударной волны искры и его движение. Обнаружены структуры полукольцевой формы, которые отождествлены с полусферическими ударными волнами, источниками которых являются процессы формирования микрократеров в областях контакта микроканалов с плоским электродом.

DOI: 10.21883/JTF.2019.01.46964.178-18

\section{Введение}

Настоящая работа является продолжением работы [1], в которой методом теневого фотографирования исследовалось развитие пространственной структуры искрового разряда в воздухе атмосферного давления в промежутке острие-плоскость в режиме однократных импульсов. Было обнаружено, что на начальной стадии разряд развивается в форме микроканальной структуры - пучка большого количества каналов микронного диаметра. Динамика структуры на временах от единиц до десятков наносекунд включает развитие микроканалов от острия вглубь разрядного промежутка их ветвление и расширение. Одновременно с этим на поверхности плоского электрода была зарегистрирована обусловленная разрядом эрозионная микроструктура в виде совокупности большого количества микрократеров.

Следует, однако, отметить, что в [1] в поле зрения оптической системы регистрации попадала только половина разрядного промежутка, включающая электродострие, что не позволяло визуализировать динамику процессов вблизи плоского электрода.

В настоящей работе с целью расширения диапазона данных проведена серия экспериментов, в которой получены тенеграммы всего межэлектродного промежутка.

\section{Экспериментальная аппаратура и методика}

Подробно экспериментальная аппаратура и методика теневого фотографирования описаны в [1]. В общих чертах эксперименты заключались в следующем. На разрядный промежуток с генератора импульсов напряжения посредством кабельной линии подавался импульс напряжения амплитудой $25 \mathrm{kV}$ и длительность фронта по уровню $0.1-0.9$ около $7 \mathrm{~ns}$. Электродная система имела геометрию „острие-плоскость“. Электрод-острие длиной $5 \mathrm{~cm}$, диаметром $15 \mathrm{~mm}$ с углом при вершине $80^{\circ}$ и радиусом кривизны $0.2 \mathrm{~mm}$ изготовлен из алюминиевого сплава. В экспериментах в качестве материала плоского электрода использовались нержавеющая сталь, медь и алюминиевый сплав.

После пробоя промежутка в разрядной цепи возникал колебательный процесс с экспоненциальным затуханием тока и напряжения. Длительность полуволны составляла $0.5 \mu \mathrm{s}$, амплитуда тока и время его затухания соответственно $1.5 \mathrm{kA}$ и $2 \mu \mathrm{s}$ [1]. За момент пробоя условно был принят момент начала роста тока и соответственно спада напряжения.

Теневая съемка разряда осуществлялась в однокадровом режиме с помощью цифрового электроннооптического регистратора. Экспозиция кадра определялась длительностью импульса зондирующего излучения. В качестве источника зондирующего излучения использовался твердотельный лазер с длиной волны $532 \mathrm{~nm}$ и длительностью импульса на полувысоте $5 \mathrm{~ns}$. Сдвигом момента запуска лазера и оптической системы регистрации относительно момента пробоя обеспечивалась визуализация различных стадий разрядного процесса. В работе [1] межэлектродный зазор составлял $3.5 \mathrm{~mm}$. В настоящих экспериментах для обеспечения съемки всего межэлектродного зазора при неизменной разрешающей способности оптической системы (не хуже $5 \mu \mathrm{m})$ межэлектродный зазор был уменьшен до $1.5 \mathrm{~mm}$.

\section{Экспериментальные результаты и их обсуждение}

На рисунке представлены тенеграммы разряда в различные моменты времени относительно пробоя. Видно, что, как и в [1], разряд развивается в микроканальной 

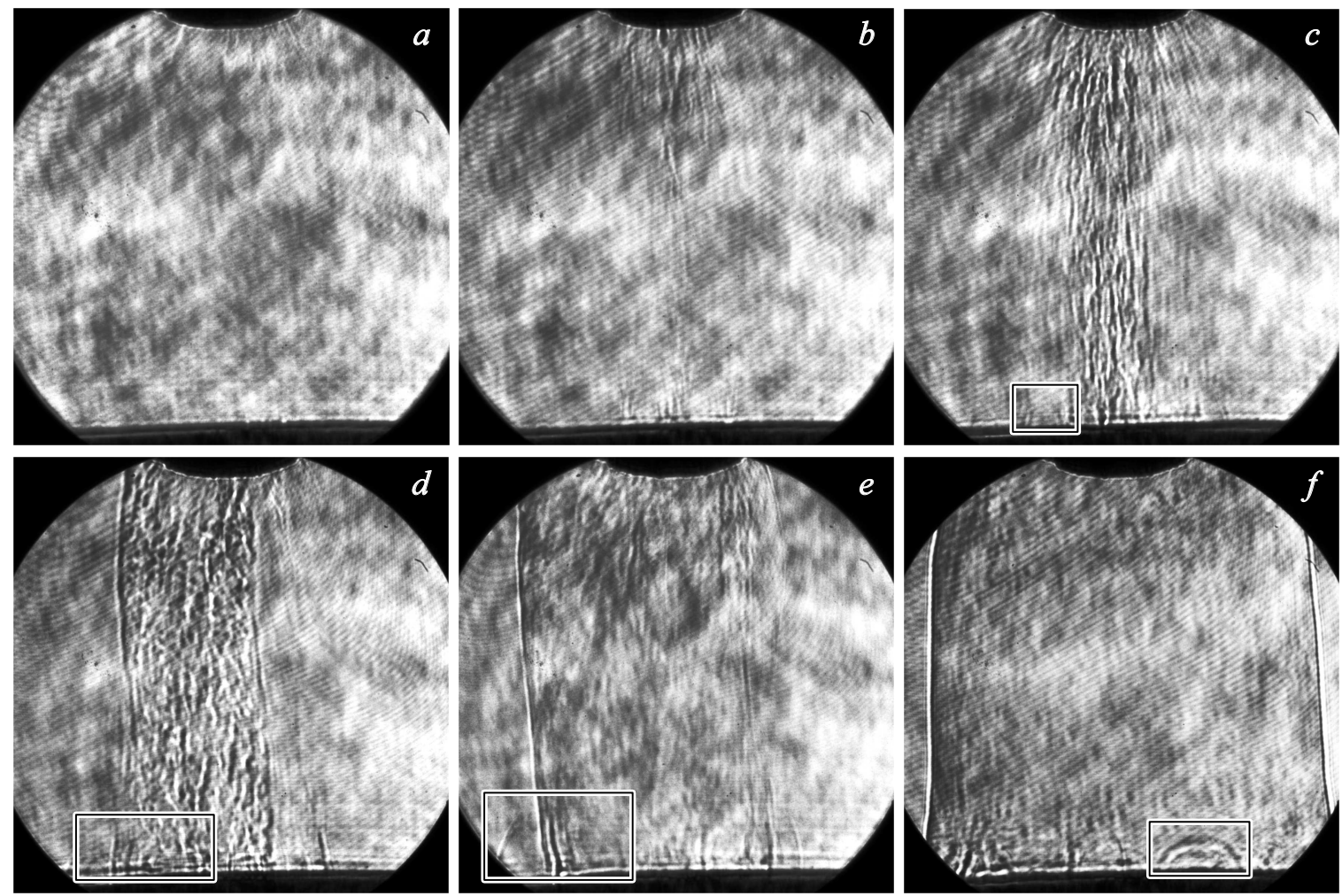

Тенеграммы разряда в различные моменты времени относительно начала пробоя: $a-0, b-5, c-30, d-70, e-135$, $f-335 \mathrm{~ns}$. Электрод-острие находится сверху, межэлектродное расстояние $1.5 \mathrm{~mm}$. Прямоугольниками выделены области присутствия полукольцевых структур.

форме. При этом раньше всего микроканалы регистрируются вблизи острия (рисунок, $a$ ), затем они развиваются вглубь промежутка, ветвятся. К $5 \mathrm{~ns}$ микроканалы регистрируются во всем промежутке, в том числе у поверхности плоского электрода, где возникают точки привязки (рисунок, $b$ ). С течением времени микроканалы расширяются (рисунки $b$ и $c$ ). Оцененная по тенеграммам скорость их расширения, по крайней мере, на временах до $30 \mathrm{~ns}$ составляет около $750 \mathrm{~m} / \mathrm{s}$, что заметно превосходит скорость звука и, по-видимому, соответствует ударному режиму расширения микроканалов. Отметим, что данное значение близко к скорости расширения микроканалов, полученной в расчетах [2] и оценках [3].

К $70 \mathrm{~ns}$ формируется общий фронт ударной волны искры (рисунок, $d$ ), скорость которой снижается от 10 до $2 \mathrm{~km} / \mathrm{s}$ на временах от 70 до $150 \mathrm{~ns}$ и затем в интервале времени от 150 до $350 \mathrm{~ns}$ находится в диапазоне от 2 до $4 \mathrm{~km} / \mathrm{s}$. На более поздних временах фронт ударной волны (граница канала искры) выходит за пределы поля зрения оптической системы регистрации.

В экспериментах [1] была зарегистрирована эрозионная микроструктура на поверхности плоского электрода. Так, на медном электроде отпечаток канала представляет собой скопление около 80 микрократеров диаметрами от 5 до $35 \mu \mathrm{m}$ [1]. Причем их количество, по-видимому, сильно занижено ввиду использования для визуали- зации оптического микроскопа с относительно малой кратностью увеличения. Более детальное исследование эрозионной структуры плоского электрода проводилось в работах $[4,5]$ с использованием сканирующего электронного микроскопа.

Полученные результаты дают основания предполагать, что микрократеры сформировались в результате выдавливания или выброса вещества материала электрода. Можно предположить, что вещество из микрократеров перешло в жидкое, сублимированное или в плазменное состояние. Для этого необходим достаточно мощный энерговклад в область микрократеров, особенно с учетом относительно высокой теплопроводности меди.

В этой связи следует особо отметить присутствие на тенеграммах вблизи поверхности плоского электрода структур полукольцевой формы, опирающихся на плоский электрод (см. рисунок). Центры этих структур расположены на поверхности плоского электрода и находятся в области разряда. Полукольцевые структуры присутствуют на тенеграммах, начиная с $30 \mathrm{~ns}$ и вплоть до выхода границы канала искры за пределы поля зрения оптической системы регистрации (на больших временах регистрация не осуществлялась).

Судя по внешнему виду указанные структуры можно отождествить с полусферическими ударными волнами, источники которых (области энерговыделения) распо- 
ложены на поверхности плоского электрода. Оценка скорости фронта волны дает значения от 1 до $10 \mathrm{~km} / \mathrm{s}$, что соответствует ударному режиму.

Данные структуры различимы на большинстве, однако, не на всех полученных тенеграммах. Причинами этого, скорее всего, являются определенная вероятность их попадания в область фокусировки оптической системы регистрации, а также „помеховое“ влияние возмущенной газовой среды в разрядной области. Видимо поэтому, наиболее четко полукольцевые структуры, точнее их части, различимы за границей канала искры - в невозмущенных областях.

Поскольку при минимальном зарегистрированном радиусе полукольцевой структуры около $100 \mu \mathrm{m}$ она обладает правильной формой, можно предположить, что источник волны „точечный“, т.е. имеет размер « $100 \mu \mathrm{m}$. Таким источником может являться процесс энерговыделения в области с пространственным масштабом, соответствующего размеру микрократера.

На некоторых тенеграммах (рисунок, $e$ ) отчетливо видно, что в центре полукольцевой структуры находится область контакта микроканала с поверхностью электрода.

Указанные факты свидетельствуют о том, что источником регистрируемых полусферических ударных волн являются процессы формирования микрократеров в области контакта микроканала с плоским электродом.

В этом случае полученные результаты позволяют сделать следующие выводы.

Во-первых, причиной формирования микрократеров являются микроканалы. Свидетельством этому является более раннее формирование микроканалов и областей их контакта с плоским электродом по сравнению с моментом появления полукольцевых структур. В противном случае эти структуры регистрировались бы и на ранних (менее $30 \mathrm{~ns}$ ) стадиях разряда, особенно в условиях невозмущенной на этих временах среды (рисунок, $a$ и $b$ ).

Во-вторых, формирование микрократеров может происходить непрерывно в течение разряда вплоть до его поздних стадий.

Исходя из полученных тенеграмм, наиболее ранние моменты появления источников полусферических ударных волн находятся в интервале от 15 до $30 \mathrm{~ns}$. Интересно отметить, что именно в этом интервале завершается формирование керна разряда, обусловливающего переход от диффузной фазы к искровой [6,7]. Кроме того, на этих временах начинается генерация рентгеновского излучения в многоканальном разряде, также обладающем микроструктурой [3].

\section{Заключение}

Методом теневого фотографирования исследована пространственная структура искрового разряда в воздухе атмосферного давления в промежутке остриеплоскость длиной $1.5 \mathrm{~mm}$.
Показано, что в начальной стадии разряд развивается в форме микроканальной структуры-пучка большого количества каналов микронного диаметра. Микроструктура раньше всего возникает вблизи острия и к $5 \mathrm{~ns}$ микроканалы регистрируются во всем промежутке, в том числе у поверхности плоского электрода.

Зарегистрирована динамика разряда на временах от единиц до сотен наносекунд, включающая развитие микроканалов от острия вглубь разрядного промежутка, ветвление, расширение микроканалов, формирование общего фронта ударной волны искры и его движение.

Обнаружены структуры полукольцевой формы, опирающиеся на плоский электрод, которые присутствуют на тенеграммах, начиная с $30 \mathrm{~ns}$ от момента пробоя. Центры структур расположены на поверхности плоского электрода и находятся в области разряда. Структуры отождествлены с полусферическими ударными волнами, распространяющимися со скоростью от 1 до $10 \mathrm{~km} / \mathrm{s}$.

Установлено, что источниками полусферических ударных волн могут являться процессы формирования микрократеров в областях контакта микроканалов с плоским электродом.

Авторы благодарны В.И. Карелину за поддержку работы.

\section{Список литературы}

[1] Алмазова К.И., Белоногов А.Н., Боровков В.В., Горелов Е.В., Морозов И.В., Тренькин А.А., Харитонов С.Ю. // ЖТФ. 2018. Т. 88. Вып. 6. С. 827-831.

[2] Тренькин А.А., Карелин В.И., Федосеев И.Г. // Ядерная физика и инжиниринг. 2014. Т. 5. № 6. С. 524-530.

[3] Buranov S.N., Gorokhov V.V., Karelin V.I., Repin P.B., Rep'ev A.G., Trenkin A.A.. Generation of high-energy electrons and X-rays in high-voltage diffuse discharges at atmospheric pressure with interelectrode gaps up to tens of centimeters. In book „Generation of Runaway Electron Beams and X-ray in high pressure gases". Vol. 1. Techniques and Measurements. Ed. V.F. Tarasenko. N.Y.: Nova Publishers, 2016.

[4] Карелин В.И., Тренькин А.А., Шибитов Ю.М., Блинова О.М., Ясников И.С. // ЖТФ. 2016. Т. 86. Вып. 10. С. 54-57.

[5] Карелин В.И., Тренькин А.А., Шибитов Ю.М., Блинова О.М., Ясников И.С. // ЖТФ. 2017. Т. 87. Вып. 9. С. 14111415.

[6] Бакшт Е.Х., Блинова О.М., Ерофеев М.В., Карелин В.И., Рипенко В.С., Тарасенко В.Ф., Тренькин А.А., Шибитов Ю.М., Шулепов М.А. // ФП. 2016. Т. 42. № 9. С. 859 870.

[7] Тренькин А.А. // Известия вуз. Физика. 2016. Т. 59. № 9/3. C. $147-151$. 